\title{
Utilization of Palm Kernel Oil (PKO) as Vegetable Oil in Making Mayonnaise with the Addition of Virgin Coconut Oil (VCO) and Palm Cooking Oil (PCO)
}

\author{
Martha Aznury ${ }^{1, *}$ Ahmad Zikri ${ }^{1}$ Aisyah Suci Ningsih ${ }^{1}$ Siti Chodijah $^{1}$ M.Arif Abdul \\ Ghoni ${ }^{1}$ Rizka Yuni Zhafira ${ }^{1}$ Nova Rachmadona ${ }^{2}$
}

\author{
${ }^{1}$ Department of Chemical Engineering, Politeknik Negeri Sriwijaya, Palembang, Indonesia \\ ${ }^{2}$ Department of Chemical Science and Engineering, Graduate School of Engineering, Kobe University, Japan \\ *Corresponding author. Email: martha_aznury@polsri.ac.id
}

\begin{abstract}
Palm kernel oil (PKO) is as oil to make mayonnaise. Mayonnaise is a mixture of vegetable oil with lime, sugar, salt, and egg yolk as an emulsifier that will form an emulsion system. This study aimed to determine the effect of adding vegetable oil to the quality of mayonnaise from PKO. The analysis carried out on the PKO is the analysis of free fatty acids, levels of impurities, and water content. Furthermore, PKO can be used in the manufacture of mayonnaise. Therefore, making mayonnaise with PKO can be analyzed by analyzing fat, protein, water, and sensory/organoleptic tests. The results showed that the addition of various types of vegetable oil: virgin coconut oil (VCO) and palm cooking oil (PCO), to based mayonnaise affected the water content, fat content, protein content, and sensory (color, aroma, taste, texture) of mayonnaise. Mayonnaise composition based on panelists assessment was obtained by mayonnaise with a composition of PKO + VCO (1:1) which contains $76.36 \%$ fat content, $8.27 \%$ water content, and $1.613 \%$ protein content.
\end{abstract}

Keywords: PKO, VCO, PCO, Mayonnaise

\section{INTRODUCTION}

Mayonnaise is a condiment that has long been known by the public and is used as a dressing sauce for food products, such as salads, burgers, pizza, sandwiches, french fries, rissoles, and sausages so on: Lime, sugar, salt, and egg yolk as emulsifiers that will form an emulsion system [1]. Emulsifiers are needed to maintain the stability of the emulsion system after shaking so that the vegetable oil and other ingredients do not separate. Emulsifiers that are not good and not in the right balance with vegetable oils cause the emulsion to be unstable. Therefore, it is necessary to know the right balance between the concentration of vegetable oil and egg yolk as an emulsifier to obtain mayonnaise that has good physicochemical properties and can be accepted by consumers [2].

The three main components of mayonnaise consist of an acid solution as a dispersion medium, egg yolk as an emulsifier, and vegetable oil as a dispersion medium [1]. Egg yolk is a very strong emulsifier (there is a type of material that has a preference for water and oil at the same time). One end of the molecule likes water, and the other end likes oil. Therefore, this material can be used as a bridge to mix fat and water ingredients. Such properties are needed in processing various types of food, such as biscuits, cakes, cakes, mayonnaise, etc. Vegetable oil in mayonnaise can reach $50-75 \%$ of the total raw material for mayonnaise [3,4]. The high concentration of oil used greatly determines the physicochemical and sensory characteristics of the mayonnaise product.

Mayonnaise from vegetable oils has developed in France, namely canola oil, sunflower oil, and olive oil. Still, mayonnaise may be made from other vegetable oils, such as Palm Kernel Oil (PKO). PKO is the kernel oil of the oil palm plant separated from the pulp and shell. This PKO is a yellowish-white oil obtained from extracting the core of the fruit of the oil palm plant [5]. PKO consists of fatty acids esterified with glycerol, the same as regular oil. PKO is semi-solid at room temperature, more saturated than palm oil but equivalent to coconut oil [6]. 
This study contains the process of utilizing PKO into mayonnaise to obtain the best mayonnaise product with various vegetable oils to know the effect of adding vegetable oil to the quality of mayonnaise from PKO.

\section{MATERIAL AND METHOD}

The tools used for analysis include a set of Soxhlet tools, UV-VIS spectrometer, analytical balance, oven, measuring flask, filter paper, hot plate, Erlenmeyer, burette, measuring pipette, beaker, thermometer.

PKO used from PT. Hindollin. Observations and measurements were carried out on the physical and chemical properties of PKO. Free fatty acids (FFAs), moisture, impurities were measured according to AOAC (2005), SNI 01-2901-2006, respectively. Then, PKO that has been produced and analyzed can be processed into mayonnaise.

Mayonnaise is made by mixing vegetable oil (PKO. VCO, PCO), fresh native chicken egg yolk, lime juice, sugar, salt, and water. The measurements were carried out on mayonnaise's physical and chemical properties, namely: Fat Content of Soxhlet Method according to Protein Content, Water Content according to AOAC (2005), and Sensory Analysis according to SNI 01-4473-1998.

The procedure for making mayonnaise is:

1. Prepare tools and materials used

2. Mix the egg yolks, sugar, and salt until the dough expands and is pale in color

3. Add oil (PKO, VCO, and PCO) little by little while continuing to shake until well blended and homogeneous.

4. Add lime juice while continuing to beat until well blended

5. If the mayonnaise is too thick, you can add water. Mayonnaise is ready to be enjoyed

\section{RESULT AND DISCUSSION} below this:

The quality of PKO can be seen in Table 1

Table 1. PKO Analysis Results Data

\begin{tabular}{cccc}
\hline \multirow{2}{*}{ Sample } & \multicolumn{3}{c}{ Parameter } \\
\cline { 2 - 4 } & $\begin{array}{c}\text { Impurity } \\
\text { Level } \\
(\%)(\mathrm{w} / \mathrm{w})\end{array}$ & $\begin{array}{c}\text { FFA } \\
(\%) \\
(\mathrm{w} / \mathrm{w})\end{array}$ & $\begin{array}{c}\text { Water } \\
(\%)(\mathrm{w} / \mathrm{w})\end{array}$ \\
\hline PKO & 0.0182 & 0.523 & 0.377 \\
\hline
\end{tabular}

\subsection{Free Fatty Acid (FFA)}

Based on the results of the analysis that has been carried out, it is obtained The FFA content of PKO was $0.523 \%$ which indicated that the free fatty acid content of the prepared PKO oil had met the standard. Based on SNI standard01-0003-1987, the quality standard of free fatty acids in PKO is 5\% maximum. Good palm kernel oil contains low free fatty acids and is bright yellow in color and easily bleached. Harvesting at the right time is one way to suppress

FFA levels while increasing oil yield. It is also necessary to ensure that only sufficiently ripe fruit should be harvested. FFA increased due to fruit damage during the harvest process until it arrived at the boiling kettle. Picking palm fruit when it is not ripe (when the biochemical process in the fruit is not perfect) produces glycerides, resulting in the formation of FFA in palm oil. Meanwhile, picking after harvest, which is marked by fruit falling and causing injury to other fruit, will stimulate the enzymatic decomposition of the fruit so that FFA levels increase [7].

\subsection{Water content}

Based on the research conducted, the water content contained in PKO is $0.2307 \%$, indicating that the $\mathrm{PKO}$ oil's water content has met the standard. Based on SNI standard01-0003-1987, the quality standard of water content in PKO is a maximum of $0.45 \%$. The presence of water in the oil can affect the quality of the oil. The water content in palm oil is determined using an oven to remove some water from the palm oil sample by evaporating the water with heat. By heating using an oven, it is expected that the water in the oil will evaporate when heated for a certain time at a temperature of $105^{\circ} \mathrm{C}$. Therefore, there is a difference in weight between before and after the water content in palm oil.

\subsection{Impurity Level}

From the study results, it can be analyzed that the level of impurities contained in PKO is $0.0182 \%$. Under these conditions, palm oil is considered to have good durability and has met the standard. By standard SNI 01-0003-1987, the standard of impurities in PKO is a maximum of $0.05 \%$. Errors in the production process generally cause increased levels of impurities in palm kernel production. The separated palm kernels are further processed to extract the oil. Before splitting, the palm kernels are dried. As a result of this drying process, the palm kernel will fade, making separating the palm kernel from the shell easier. The separation of the palm kernel is done by separating the palm kernel from the palm kernel waste, which includes the shell, a 
combination of whole seeds, semi-broken seeds, shells, and other impurities [8].

The quality of PKO can be seen in Table. 2

Table 2. Data Analysis of Mayonnaise

\begin{tabular}{cccccc}
\hline & \multicolumn{3}{c}{ Composition } & \multicolumn{3}{c}{ Parameter } \\
\cline { 2 - 6 } Oil Type & $\begin{array}{c}\text { Oil } \\
(\mathrm{ml})\end{array}$ & $\begin{array}{c}\text { Egg } \\
\text { yolk } \\
(\mathrm{g})\end{array}$ & $\begin{array}{c}\text { Rate } \\
\text { fat } \\
(\%) \\
(\mathrm{w} / \mathrm{w})\end{array}$ & $\begin{array}{c}\text { Water } \\
\text { content } \\
(\%) \\
(\mathrm{w} / \mathrm{w})\end{array}$ & $\begin{array}{c}\text { Protei } \\
\mathrm{n} \\
\text { Level } \\
(\%) \\
(\mathrm{w} / \mathrm{w})\end{array}$ \\
\hline PKO & 60 & 40 & 72.23 & $\begin{array}{c}11.509 \\
4\end{array}$ & 1.091 \\
$\mathrm{PKO}+\mathrm{VCO}$ & $30:$ & 40 & 76.36 & 9.9806 & 1,613 \\
$(1: 1)$ & 30 & & & & \\
PKO+ PCO & $30:$ & 40 & 92.13 & 7.0476 & 1.397 \\
$(1: 1)$ & 30 & & & & \\
$\begin{array}{c}\text { PKO + VCO } \\
(2: 1)\end{array}$ & $40:$ & 40 & 73.65 & 10,517 & 1.545 \\
$\begin{array}{c}\text { PKO + PCO } \\
(2: 1)\end{array}$ & $40:$ & 40 & 86.21 & 8.2746 & 1,124 \\
\hline
\end{tabular}

\subsection{Effect of Comparison of PKO, VCO, and Palm PCO on Mayonnaise Fat Content}

Figure 1 shows that the treatment of various types of vegetable oil in the manufacture of mayonnaise produces different fat levels. Treatment of types of vegetable oil in the manufacture of mayonnaise with PKO, PKO + VCO (1:1), PKO + PCO (1:1), PKO + VCO (2:1), and PKO + PCO (2:1) resulted in the average fat content was $72.23 \%, 76.36 \%, 92.13 \%$, $73.65 \%$, and $86.21 \%$. The highest fat content was found in PKO + PCO (1:1) of 92.13\%, and the lowest fat content was found in mayonnaise with a PKO content of $72.23 \%$. The fat content produced by PKO, VCO, and PCO treatment has met the mayonnaise quality requirements of SNI 01-4473-1998, where it has been determined that the standard fat content of mayonnaise is at least $65 \%$.

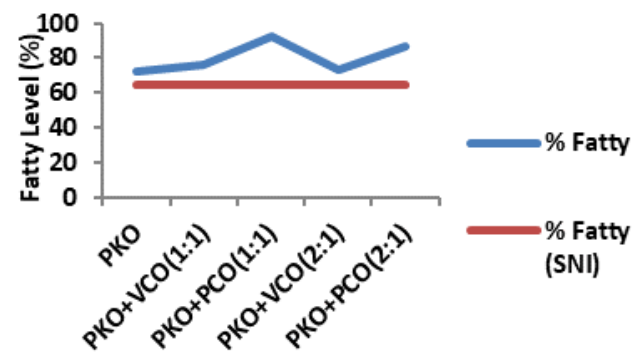

Figure 1. Effect of Comparison of Composition of PKO, VCO, and Palm PCO on Mayonnaise Fat Content

According to Fitryaningtyas and Widyaningsih (2015) [9], the increase in fat content is due to increasing fat by the hydrophilic group of egg yolk lecithin. Lecithin in egg yolk functions as an emulsifier that can bind water and fat. Lecithin has two different groups, namely hydrophilic bonds and hydrophobic bonds because of the high saturated fatty acids in the palm PCO used, which contains $41 \%$ saturated fat, PKO and coconut oil-based on fatty acid content are classified into lauric acid oil because their lauric acid content is the largest when compared to other fatty acids [10]. PKO has a lauric acid content of $48.07 \%$ [11].

\subsection{The effect of the comparison of $\mathrm{PKO}, \mathrm{VCO}$, and $P C O$ on the water content of mayonnaise}

Figure 2 shows that the treatment of various types of vegetable oil in the manufacture of mayonnaise resulted in different water content. The highest water content was found in the use of PKO of $11.509 \%$, and the lowest water content was found in PKO + PCO (1:1) oil of $7.0476 \%$. The water content produced by $\mathrm{PKO}$, VCO, and oil treatment

Palm oil has met the quality requirements of mayonnaise (SNI 01-4473-1998), where it has been determined that the standard water content of mayonnaise is a maximum of $30 \%$.

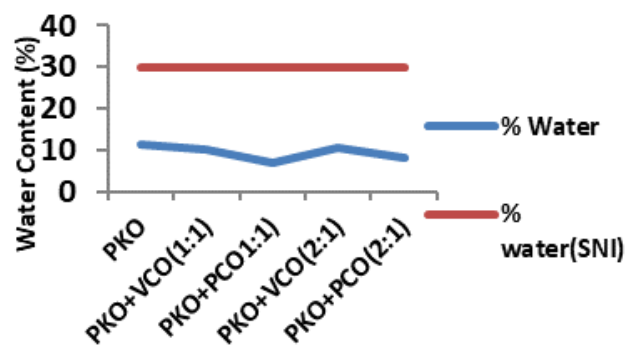

Figure 2. Effect of Comparison of Composition of $\mathrm{PKO}, \mathrm{VCO}$, and Palm PCO on the water content of mayonnaise

According to Fitryaningtyas and Widyaningsih (2015) [9], the correlation between water content and fat content is negative. The higher the fat content, the lower the water content. The water content of the mayonnaise produced is obtained from the water content of the raw materials used, namely egg yolks, lemons, and the addition of water. Chicken egg yolk has a water content of about $49.4 \%$ per $100 \mathrm{~g}$. However, the formula in this study for the addition of egg yolks, lime juice, and warm water was used the same so that the difference in fatty acid content in each vegetable oil contributed to the water content. Although water plays an important role for an emulsion product, namely in balance to the proportion of oil and protein, the water content is one of the requirements for the quality of mayonnaise. 


\subsection{Effect of Comparison of $P K O, V C O$, and Palm PCO on Mayonnaise Protein Levels}

According to the analysis that has been carried out on the type of vegetable oil treatment in the manufacture of mayonnaise with PKO, PKO + VCO (1:1), PKO + PCO (1:1), PKO + VCO (2:1), and PKO + PCO ( 2:1) resulted in the average protein content of mayonnaise respectively $1.091 \%, 1.397 \%, 1.613 \%, 1.124 \%$, and $1.545 \%$. Thus, the protein content produced by the four treatments met the mayonnaise quality requirements (SNI 01-4473-1998), which contained at least 0.9\% protein content. The following bar chart of mayonnaise protein content can be seen in Figure 3.

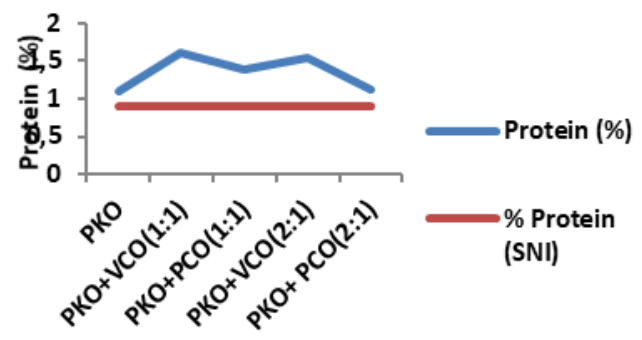

Figure 3. Effect of Comparison of PKO, VCO, and Palm PCO Composition on Mayonnaise Protein Levels

According to Thomas (2012) [12], all fats and oils or fats in food contain a certain amount of phosphorus-fat. Phosphorus is a mineral found in foodstuffs with high protein content, while coconut (as the basic raw material for coconut oil) is a food ingredient with high protein. Mayonnaise protein is a high-quality protein because it comes from egg yolks which contain essential amino acids.

\section{CONCLUSION}

1. Mayonnaise products are obtained from PKO and VCO \& palm PCO that already meet the standards (SNI 01-4473-1998).

2. The best mayonnaise composition based on panelists' assessment was obtained by mayonnaise with a composition of PKO + VCO (1:1) which contains $76.36 \%$ fat content, $8.27 \%$ water content, and $1.613 \%$ protein content.

\section{ACKNOWLEDGMENTS}

The authors acknowledge funded by the Directorate General of Higher Education, Ministry of Education and Culture, in accordance with the Agreement for the Implementation of Research Assignment of advanced student lecturer Number: 7604/PL6.2.1/PG/2021 dated 21 September 2021

\section{REFERENCES}

[1] Z. Ma, J.I. Boye, Advances in the Design and Production of Reduced-Fat and ReducedCholesterol Salad Dressing and Mayonnaise: A Review, Food Bioprocess Technol. 6 (2013) 648670. https://doi.org/10.1007/s11947-012-1000-9.

[2] M. Taslikh, N. Mollakhalili-Meybodi, A.M. Alizadeh, M.M. Mousavi, K. Nayebzadeh, A.M. Mortazavian, Mayonnaise main ingredients influence on its structure as an emulsion, J. Food Sci. Technol

(2021) https://doi.org/10.1007/s13197-021-05133-1.

[3] K. Hunsakul, S. Siripongvutikorn, W. Usawakesmanee, Utilization of tuna roe and using inulin as oil replacer for producing value added omega-3 mayonnaise product, Funct. Foods Heal. Dis. $6 \quad$ (2016) 158-172 https://doi.org/10.31989/ffhd.v6i3.242.

[4] M.R. Ali, R.M. EL Said, Assessment of the potential of Arabic gum as an antimicrobial and antioxidant agent in developing vegan "egg-free" mayonnaise, J. Food Saf. 40 (2020). https://doi.org/10.1111/jfs.12771.

[5] D.S.K. Tobing, Development of downstream agribusiness in the context of increasing value added products cpo, (2012) 601-614.

[6] S. Parsons, S. Raikova, C.J. Chuck, The viability and desirability of replacing palm oil, Nat. Sustain. 3 (2020) 412-418. https://doi.org/10.1038/s41893020-0487-8.

[7] Z. Kaniuga, Chilling response of plants: Importance of galactolipase, free fatty acids and free radicals, Plant Biol. 10 (2008) 171-184. https://doi.org/10.1111/j.1438-8677.2007.00019.x.

[8] I.I. Misnon, N.K.M. Zain, R. Jose, Conversion of Oil Palm Kernel Shell Biomass to Activated Carbon for Supercapacitor Electrode Application, Waste and Biomass Valorization. 10 (2019) 17311740. https://doi.org/10.1007/s12649-018-0196-y.

[9] S.I. Fitriyaningtyas, T.D. Widyaningsih, The Effect of Lecithin and CMC Against Physical, Chemical and Organoleptic Apple Manalagi Margarine ( Malus sylfertris Mill ) which Supplemented with Peanut Oil, J. Pangan Dan Agroindustri. 3 (2015) 226-236.

[10] A.M. Marina, Y.B. Che Man, S.A.H. Nazimah, I. Amin, Monitoring the adulteration of virgin coconut oil by selected vegetable oils using differential scanning calorimetry, J. Food Lipids. 16 (2009) 50-61. https://doi.org/10.1111/j.17454522.2009.01131.x. 
[11] J. Silalahi, Lida Karo Karo, S.M. Sinaga, Yosy Cinthya Eriwaty Silalahi, Composition of Fatty Acid and Identification of Lauric Acid Position in Coconut and Palm Kernel Oils, Indones. J. Pharm. Clin. Res. (2018) https://doi.org/10.32734/idjpcr.v1i2.605.

[12] A. Thomas, Fats and Fatty Oils, Ullmann's, Wiley-VCH Verlag GmbH \& Co. KGaA, Weinheim, 2012. https://doi.org/10.1002/14356007.a10_173. 